\section{THE OPERATIVE TREATMENT OF INGUINAL HERNIA}

\section{RESULTS OBTAINED IN ADULT MALES BY THE FASCIAL SUTURE TECHNIQUE}

BY

W. GRAY, M.B., Ch.B.

Surgical Registrar, Stobhill Hospital, Glasgow

The short paper by A. Simpson-Smith (1939) should help to disturb the all-too-complacent attitude towards the results of operations for the radical cure of hernia. The recurrence rates which he quotes make it quite clear that the results generally obtained leave much to be desired. The limitations of the usual methods of hernial repair have long been recognized in this clinic, and for some years past the fascial suture technique has been employed in an effort to produce better results.

Two years ago we attempted to find out what improvements had been gained by the fascial suture operation. Unfortunately the social condition of our patients makes follow-up investigations very difficult, and we were able to trace only fifty out of a total of approximately 200. At that time this seemed too small a series to publish; but since the question of recurrence rates is now often raised it may be of value to state the results obtained. Since four of the fifty patients had bilateral lesions we have information about fifty-four hernias. Of these, twentynine were oblique, ten were direct, and in eleven the type was not stated in the records. The remaining four cases had already recurred after operation elsewhere. The average period which had elapsed between operation and the date of the investigation was three years, so that a fair opportunity was given for recurrences to appear. The ages of the patients ranged from 18 to 66 years, with the following distribution:

\begin{tabular}{c|c|c|c|c|c}
\hline $\begin{array}{c}-20 \\
\text { years }\end{array}$ & $\begin{array}{c}20-30 \\
\text { years }\end{array}$ & $\begin{array}{c}30-40 \\
\text { years }\end{array}$ & $\begin{array}{c}40-50 \\
\text { years }\end{array}$ & $\begin{array}{c}50-60 \\
\text { years }\end{array}$ & $\begin{array}{c}60+ \\
\text { years }\end{array}$ \\
\hline 1 & 3 & 15 & 12 & 15 & 4 \\
\hline
\end{tabular}

Technique.-The main points of the technique used in this series are: the sac was not cut away after being separated, but was stitched and pulled up under the internal oblique muscle after Macewen's method; the fascial suture was derived from the aponeurosis of the external oblique and was inserted in front of the cord. The conjoined tendon was not utilized as it is often of poor development and little strength. Instead the fascial stitches passed from Poupart's ligament to the edge of the sheath of the rectus abdominis without tension.

\section{Results}

It is fair to say that the efficiency of a hernial repair is severely tested by the type of patient we treat in this hospital. In the first place our patients age prematurely, so that, generally speaking, the reparative powers of the tissues of a man of 40 to 50 years are approximately equal to those of a man of 50 to 60 years in better social and financial circumstances. Secondly, chronic bronchitis is common and is regarded almost as normal in patients over 40 years. Lastly, many of our patients have heavy manual employment, such as that of general labourers, ships' firemen, and dock workers. The investigation revealed that in the fifty-four repairs there were four recurrences, giving a rate of 7.4 per cent. The details of the recurrent cases are as follows:
Case 1.-Aged 42. The original hernia was oblique and on the right side. At the time of operation chronic bronchitis was present. The rupture occurred twelve months after operation, and when examined three years after operation was a mere bubonocele. In the interim a left-sided:hernia had developed. Cough was so severe that further operation was not advised.

Case 2.-Aged 38. The original hernia was on the left side, but the type was not stated. Moderately severe chronic bronchitis was present. The patient was not sure when the rupture recurred, but thought it probably came back about a year after operation.

Case 3.-Aged 52. The original hernia was on the right side and was direct. It recurred six months after operation. A note made at the time of operation states: "Abdominal wall very poor. Repair not satisfactory."

Case 4.-Aged 48. The original hernia was on the right side, but the type was not recorded. It recurred after seven months. The patient's work was moderately heavy.

\section{Commentary}

Twenty-five of the operations were done by Mr. J. E. Paterson, consulting surgeon, with but one recurrence (Case 1, described above). The rest were performed by registrars, all of whom were beginning their operative experience. Spinal anaesthesia ( 0.1 gramme planocaine) was used almost exclusively in this series. This is an important point, as it prevents the strain of post-anaesthetic vomiting. The damage that retching can cause was vividly demonstrated to me recently when a neurotic patient was undergoing a hernial repair under spinal anaesthesia. Just when the fascial suture had been inserted the patient began to retch. A tearing noise was heard, and examination showed that the strain had torn a long strip completely away from Poupart's ligament and the repair was rendered useless.

Two of the recurrences may fairly be ascribed to the strain of chronic coughing and not to any defect in technique. Case 3 was unsuitable for this type of operation. A more secure repair could have been made with long fascial sutures obtained from the fascia lata.

It -was discovered that when a hernia did recur it ran alongside the cord and appeared at the side of the original external ring. Because of this the technique has been modified. The fascial suture is now inserted behind the cord. Great care is taken to insert the first stitch so that no gap is left at the angle between the edge of the rectus sheath and the pubic crest. In cases where Poupart's ligament is lax and poorly developed the first stitches are passed through Cooper's ligament instead.

\section{Summary}

A small series of fifty-four cases of inguinal hernia treated by fascial suture is described.

The recurrence rate is 7.4 per cent.

Very little selection of cases for operation was carried out. Thus moderately severe chronic bronchitis was not in itself considered a contraindication; no distinction was made between direct and oblique types, and hernias which had already recurred were not excluded. In short, if there was a reasonable chance of curing the hernia without endangering the patient's life operation was performed.

Considering the clinical material the results are gratifying, but an improvement is expected from the modified technique.

This investigation was carried out at the suggestion of Mr. J. E. Paterson, to whom I am indebted for his stimulating interest in all my work. I must also thank Dr. W. Martin, superintendent, for permission to publish this paper and for his frequent words of encourägement. 